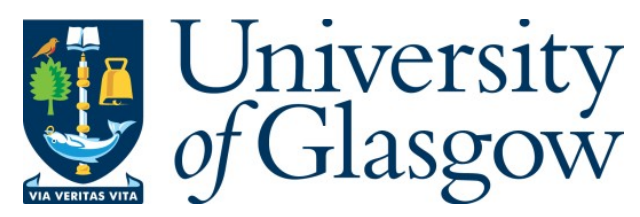

Arizpe, E. (2019) Migrant shoes and forced walking in children's literature about refugees: material testimony and embodied simulation. Migration Studies. (Early Online Publication)

(doi: 10.1093/migration/mnz047)

This is the Author Accepted Manuscript.

There may be differences between this version and the published version. You are advised to consult the publisher's version if you wish to cite from it.

$\underline{\text { https://eprints.gla.ac.uk/202789/ }}$

Deposited on: 11 November 2019

Enlighten - Research publications by members of the University of Glasgow http://eprints.gla.ac.uk 


\title{
Migrant Shoes and Forced Walking in Children's Literature about Refugees: Material Testimony and Embodied Simulation
}

\author{
Evelyn Arizpe ${ }^{1, *}$ \\ ${ }^{1}$ School of Education, University of Glasgow, Glasgow, G3 6NH, United Kingdom \\ * Corresponding author: School of Education, University of Glasgow, Glasgow \\ Email: evelyn.arizpe@glasgow.ac.uk
}

Tel. 07855885280

\begin{abstract}
Increasing numbers of children's books on the topic of refugees are appearing in publishers' catalogues around the world, raising awareness of diverse contexts of forced migration and of the hardships faced by children and their families in this situation. Yet few studies have analysed in depth how aesthetic and literary strategies work to engage readers with the refugee experience in these well-intentioned attempts. Drawing on a corpus of refugee texts, from picturebooks to young adult books, which draw attention to the material, the corporeal and the symbolic aspects of shoes and forced walking, in this article, I look at materiality and mobility (or immobility) and analyse how text and image create three main points of connection between the narrative and the reader: appropriate footwear; physical discomfort/pain and what I have termed as 'the chronotope of forced migration'. I discuss how calling attention to these connections is used as a strategy to create an 'embodied simulation' (Bergen 2016) which encourages readers to 'walk in refugee shoes' and adopt a more empathetic stance. Examining these strategies shows how it is possible to engender an understanding of the refugee situation through text and/or image in ways that allow a level of emotional engagement even when young readers have not experienced these circumstances directly. Understanding how these aesthetic and literacy strategies work can help to support the claims made for the role of children's literature in fostering empathy as well as the pedagogical use of this literature by teachers and other professionals.
\end{abstract}

Keywords: children's literature, refugee texts, shoes, forced walking, empathy

\section{Introduction}

In a recent novel marketed for young adults, Salt to the Sea by Sepetys (2016), refugees are trying to escape the advancing Red Army in 1945 and hoping to board the Wilhelm Gustloff, a ship meant to take them to safety (instead, the ship was torpedoed by a Soviet submarine 
with an estimated 9000 people losing their lives). Among the group of characters making their way towards the ship is a shoemaker: 'The old man spoke of nothing but shoes. He spoke of them with such love and emotion that a woman in our group had crowned him "the shoe poet."' (Sepetys 2016: 14-15). The shoe poet warns the others that, "'Poorly made shoes will torture your feet, inhibit your progress. Then you will stop [...] And then you will die"" (Sepetys 2016:13). He later adds: “The shoes always tell the story” (Sepetys 2016: 15).

In studying a corpus of children's books on the theme of migration and refugees (henceforward referred to as 'refugee texts') published in English between 2005 and 2018, set in different international contexts and which range from picturebooks to Young Adult literature, I noticed that in many of them, shoes do 'tell the story'. Along with the impact of the physical landscape on the body and particularly the feet, shoes play an emotive and symbolic role in engaging readers with the refugee experience. This is done through specific narrative techniques that reference the material and metaphoric nature of shoes; the pain or discomfort of wearing inappropriate footwear and the descriptions of forced walking. In what follows, I analyse the aesthetic and literary strategies around materiality and mobility (or immobility) in both text and image that create three main points of connection between the narrative and the reader: appropriate footwear; physical discomfort/pain and what I have termed as 'the chronotope of forced migration'. Through references to the material, the corporeal and the symbolic aspects of shoes (Riello and McNeil 2006; Dant 1999) and forced walking, the connections encourage an 'embodied simulation' (Bergen 2016) which encourages readers to 'walk in refugee shoes' and adopt a more empathetic stance (Nikolajeva 2014a). I illustrate these connections with examples from the corpus of refugee texts which draw attention to shoes and/or forced walking. 
Whether stories are fictional or real, shoes often "tell the story" about migrants and migration. An Oxfam report published in June 2018 from the France/Italy border described the inhuman conditions in which child migrants were being held by French border guards; among other things, the report accuses guards of cutting the soles of the children's shoes as a way of saying, 'Don't try to come back' (Giuffrida 2018). Also in June 2018, the Associate Press reported that Algeria has expelled more than 13,000 people over the past year, forcing them to walk, without food or water into the Sahara Desert, including pregnant women and children. One reporter commented that even the thickest shoes offer no protection from the burning sand (Independent 2018).

As material objects of clothing that are part of most people's lives, shoes offer protection from the elements and the terrain and are often important in accessing food, healthcare and education. They may also be essential to walk or run to safety in the case of some of the 31 million children who are forcibly displaced (UNICEF 2018). As symbolic objects, shoes have a myriad of meanings, and the cutting of soles in the first news story is a cruel example of how powerful this meaning can be. Descriptions of the forced walking endured by many refugees, as in the second news story and in many others, also bring home the pain they suffer, especially when it involves walking barefoot or in unsuitable shoes.

In the growing number of publications for children and young adults which raise awareness about migration and refugees, authors and illustrators turn to persuasive narrative techniques, such as metaphor, imagery and the powerful fusion of words and images to convey a sense of danger, fear, loss and pain, yet all within the safe space created by fiction. Because shoes are familiar objects and walking is a physical human act which most readers have experienced, they act as literary and visual devices which invite even young children to imagine what the refugee experience might be like (1). Shoes are not only material extensions of an individual 
body that lessen the physical impact of geographical terrains and allow mobility, they can also stand as metaphors for other bodies. The act of walking, with the physical, mental and emotional strain it involves when it is forced, is also both physical and symbolic.

Refugee fiction for children and young adults tends to deal with issues during one or more of the three stages of the refugee experience as identified by Fazel and Stein (2002): the circumstances in the country of origin that lead to leaving; the dangers and hardships during the flight to safety; and the difficulties encountered on arrival, whether at a refugee camp or at the country of refuge. Inviting life-to-text analogies at these different points in the migrant experience by calling attention to objects and characters' actions which readers can relate to (such as food or acts of friendship) is a valuable narrative strategy because it invites the reader to relate events to their own concerns (Oatley 2016: 621). According to Bergen (2016), 'embodied simulation' is one of the ways in which the mind, the brain and the body use language to make meaning or 'construct mental experience of what it would be like to perceive or interact with objects and events that are described in language' (142). Bergen focuses on language rather than images, but picturebook scholars like Nodelman (1988), Arizpe and Styles (2003) and Nikolajeva and Scott (2006) have long been highlighting the significance of the visual aesthetic in books for children. Nikolajeva (2014a \& b) argues that the intrinsic interaction between text and image which defines a picturebook (Nodelman 1988) also calls attention to embodied emotional meaning-making processes.

Recent literary scholarship on the educational project of using refugee texts to raise awareness of diversity and migration (Arizpe, Bagelman, Devlin, Farrell and McAdam 2014, Evans 2015, Dolan 2014, Hope 2017, McAdam 2018), tends to assume that 'children's literature cultivates an empathetic imagination' (Nel 2018: 358). While these studies suggest that reading these texts can be transformative, up to now there has little in-depth examination 
of how specific aesthetic and literary strategies work to engage readers' cognition and affect in ways that could indeed promote empathy, change perspectives and lead to social action. Also, as far as I could ascertain, neither shoes nor the strain of walking on the body, have been addressed in either literary or empirical studies that involve refugee texts. This is surprising because although children's and young adult's books about migration describe many types of journeys and different forms of travel, in these contexts shoes and moving forward can mean the difference between mobility and immobility, and even between life and death.

Therefore, in this article I explore how both textual and visual references to the material, the corporeal and the symbolic aspects of shoes and forced walking seek to trigger cognitive processes which might stimulate social and affective reactions. This 'embodied simulation' (Bergen 2016) allows even young children to understand how characters think and feel, thus encouraging readers to adopt a more empathetic stance (Nikolajeva 2014a \& b). In order to understand how this is achieved, it is necessary to look first to material culture studies and, later, to cognitive narratology.

Material culture studies remind us to notice the things that are so much part of the practice of daily life that we often take them and our relationship with them for granted, forgetting they are a product of, and embody, social relations. While objects in material culture are often seen from the perspective of consumption, I subscribe to Dant's proposition which goes beyond that to note that, '[a]11 objects are social agents in the limited sense that they extend human action and mediate meanings between humans' (Dant 1999: 13). Given the importance of cultural artefacts for those who migrate, it is surprising that only recently attention has been drawn to the relationship between material culture and migration. In their introduction to a special issue on this theme, Basu and Coleman argue for the "intertwining of 
material culture and mobility" (2008: 316) in migration studies and also the need to consider "connections between the material and the temporal in migrant contexts" and "notions of embodiment" (321). In educational studies using children's literature, the only empirical study I could find that considers the role of material artefacts in refugee texts is that of McAdam who describes how teachers can invite conversations around the role of valued cultural artefacts in children's lives as "a means of prodding the boundaries of otherness to foster care for another in a context that cannot be directly experienced" (McAdam 2018: 4).

In what follows I will explore materiality and mobility (or immobility) in the refugee context as reflected in the presence or lack of shoes to highlight the refugee plight and/or scenes of forced walking, whether textual or visual in children's refugee texts. Before discussing them, however, it is necessary to refer briefly to the history and cultural connotations of footwear in the context of children's literature and accounts of footwear in non-fictional contexts because in both cases they provide background and imbue the materiality of the shoe with significance. This will lead to the next section which refers to cognitive theories that help explain how it might be possible to 'walk in someone else's shoes'.

\section{Connotations of footwear in narratives about mobility}

In symbolic associations that transcend cultures, shoes 'tell the story' of poverty, wealth, vanity, endurance, cleverness and clumsiness among other things. Like many other things that form part of human material culture, ' ...footwear acquires different meanings related to sex, attractiveness, group membership and power (Riello and McNeil 2006: 3); in other words, like other material objects, they reflect and affect 'our values, our actions and our lifestyles' (Dant 1999: 2). Writing about the history of shoes, Riello and McNeil note that shoes 'are the principal intersection between the body and physical space and allow us to 
move in, and experience, the environment' (2006: 3). Because of their impact on physical movement, they are intrinsic to playing, running, climbing, escaping and dancing, but they can also pinch, cause blisters and force one to stay still. They are consumables with a limited lifespan, affected by wear and tear, and at the same time, often objects of desire. When references to shoes are made in books, even very young readers can relate to them personally and emotionally in ways that can become part of our earliest memories: the pleasure or disappointment over new shoes or the discarding of beloved old ones; the pain caused by ill-fitting shoes and the pleasure or discomfort of walking barefoot. Shoes are also used as testimony: they are a reminder of those who no longer live to fill them and the reasons for this, as evidenced in the powerful exhibitions that involve shoes in museums around the world about war and the Holocaust; in the Chinese artist Ai Wei Wei's installation of clothing discarded at the Idomeni refugee camp along the GreekMacedonian border (Pogrebin 2016) or the setting out of 7000 pairs of shoes outside the American Capitol Building in remembrance of the schoolchildren killed by gun violence in the United States (Quackenbush 2018). These artefacts, along with photographs of refugee children and in particular the shocking image of the body of Alan Kurdi lying on a beach, having drowned in the Mediterranean (https://en.wikipedia.org/wiki/Death_of_Alan_Kurdi), convey the embodied experience of refugees, raise awareness and promote empathy through their symbolic power.

Shoes are closely linked to the refugee experience because they enable or prevent mobility. Historical and current accounts of migration, such as the ones referred to below, often mention shoes as well as stressing the physical hardship of walking on extreme terrains and under severe climatic conditions, as a result of having to find ways across borders that are less likely to be policed. In these accounts, what comes through is the immense strain and 
suffering as the migrants walk away from the crises that have forced them to leave their home. As long as there is mobility, there is hope; the alternative, standing still, can mean abandonment, capture or even death. One non-fictional account which highlights this can be found in the bestselling book, In the Sea there are Crocodiles (Geda 2012), based on the life story of Enaiatollah Akbari, a 10-year-old Afghani boy whose journey from his home to Italy and asylum took five years. At one stage, he is crossing the mountains from Iran to Turkey with traffickers and other migrants, walking for weeks in the blazing sun and freezing snow. A boy from Bengal falls and can't continue walking but he is too heavy to carry, so they are forced to abandon him. On the eighteenth day they find a group of people sitting on the ground, frozen to death and Enaiatollah takes one of their shoes as he passes:

All the others sidled silently past them. I stole the shoes from one of them, because mine were ruined and my toes had turned purple. I couldn't feel them any more, even if I hit them with a stone. I took the shoes and tried them on. (Geda 2012: 125-6)

Approximately 14,000 km away from the mountains crossed by Enaiatollah and other migrants into Turkey, migrants from South and Central America, Mexico, Haiti and even Africa and the Middle East, experience much of the same pain and suffering as they attempt to cross into the United States. De Leon (2015), an American ethnographer, carried out a study of the migrant journey across the desert that encompasses both sides of some stretches of the Mexico-US border, where temperatures can reach 100 degrees Farenheit. Among the discarded objects in the desert he collected and studied are shoes which he uses to try and reconstruct the untold stories of those who have undertaken that perilous journey. De Leon describes the special market on the Mexican side where migrants buy some of the most important gear they need for this journey: trainers with carpeted soles that prevent the wearers from leaving footprints, foot powder, extra socks for the blisters, pain medication for 
sore legs, glue to fix shoes, bandages for sprained ankles (de Leon 2015: 160). The discarded shoes he finds evidence the 'intense trauma from walking' and '[T]hose who can't keep up with a group because of blisters or worn-out shoes are often left behind, which can be a death sentence.' (de Leon: 181) His encounters with some of those who made it back to Mexico include people in hospital with heavily bandaged feet who, along with stories of rape and kidnapping, speak of shoes stolen by bandits and of trying to walk barefoot or in socks.

Although de Leon does not include children in his study, in the last 15 years increasing numbers of children have attempted this dangerous crossing, often with strangers (Thomson 2003). Whether they cross through the desert or at other border points, every year thousands of children 'face life-threatening situations during the journey' (Menjívar and Perreira 2017: 11) and the same applies to child refugee journeys anywhere else in the world. The stressful events which are risk factors for mental health problems (Fazel and Stein 2002) are reflected in refugee texts, such as witnessing death, observing the helplessness or depression of a parent, experiencing poverty and/or separation from parents, waiting for 'immigration status to be determined' and other legal issues to be resolved, spending a long period of time in a refugee camp and undergoing a high number of transitions on the way to their destinations. Incorporating these real-life factors into fictional narratives allows readers a glimpse into what the refugee experience.

\section{Walking in a refugee's shoes}

Having identified the material and testimonial role of the shoe within the context of forced migration, this section extends the metaphoric role of shoes and walking by considering the notion of 'walking in someone else's shoes'. It is a much-quoted phrase which famously appears in Lee's novel, To Kill a Mockingbird when Atticus, the lawyer, tells his daughter 
'... you never really know a man until you stand in his shoes and walk around in them' (Lee 1977: 308). One way of having this 'other-shoe experience' is through engagement with literary fiction. The mechanisms which allow this to happen, which explain how and why readers can imagine and care about a character's feelings, are being studied by cognitive psychologists (see Oatley's 2016 review of these studies) who have found that reading can 'prompt improvements in empathy and theory-of-mind' (Oatley 2016: 618). This happens when literary and aesthetic mechanisms trigger cognitive processes in the reader's mind which initiate and sustain empathetic engagement with fiction and allow readers to experience 'embodied simulation' (Bergen 2016) with some measure of the intense emotions that accompany these experiences. The work of Mar and Oatley maintains that this 'deeplyfelt simulation of social experience' that stories offer can lead to better social understanding (Mar, Oatley and Petersen 2009: 4018).

Given that reading is considered to foster the abilities of theory-of-mind and empathy (Mar, Oatley and Petersen 2009) and that both are considered necessary to foster a better sense of self as well as social understanding, literature for children is often seen as a valuable tool for education and socialization. This helps to explain the drive to write, publish and teach using texts that offer the 'other-shoe experience' such as refugee texts. However, because the concept of empathy has been looked at from so many different disciplinary perspectives (Batson 2009), questions have been raised about the kind of empathy that reading children's fiction can really support, with Mallan, for example, making the valid point that feeling empathy as an individual does little to change the power structures that may have created the need for empathy in the first place (Mallan 2013: 113). An in-depth exploration of the nuances of empathy and the link between empathy and social action is beyond the scope of this article, but among the eight types of empathy identified by Batson (2009) the two I 
consider here are 'knowing someone else's internal state, including his or her thoughts and feelings' or 'cognitive empathy' (Batson 2009: 1) and 'imagining how another is thinking and feeling' which Batson notes has been referred to as 'psychological empathy' or 'perspective taking' but which I prefer to call 'affective empathy'. While I'm aware that these two types at least are more blurred than distinct, I will argue that the potential for fostering both cognitive and affective empathy exists in refugee texts and it can be found embedded in the material, corporeal, symbolic and metaphoric devices of the text, such as shoes, which readers respond to during the act of reading.

The significance of the interaction between the text and what the reader brings to the text has already been highlighted by reader-response theories (Iser 1978, Rosenblatt 1978). Rosenblatt argues that it is in the 'transaction' (Rosenblatt 1978) between the text and the reader, that meaning is made, and while the reader brings their knowledge and experiences to the event, at the same time the text has an influence on the reader's perception of themselves and the world. The interactive process of life-to-text and text-to-life is linked to a sociocultural view of reading that considers the 'connections of texts to engagement in and simulations of actions, activities, and interactions - to real and imagined material and social worlds' (Gee 2001: 714). In the analysis below, I look at some of the 'connections' that support these simulations, through the language, cultural signs and symbols in a text which parallel the sensory and/or emotional states the reader has experienced through characters involved in similar activities.

Cognitive narratology in children's and young adult's literature takes these ideas further by exploring childhood cognition, moving ‘theoretical discussions of children's texts away from the purely discursive and toward a recognition of the material', and this materiality includes, among other things, embodiment as well as cultural artefacts (Seelinger Trites 2017: 108). So 
far, Nikolajeva has provided the most detailed exploration of why and how children's books can become a 'training field' (Nikolajeva 2014a: 94) for cognitive and affective skills. Drawing on cognitive theory, she shows how this 'training' is carried out as children's literature both adjusts to and challenges its audience, offering aesthetic expressions that stimulate higher-order mental activity through imagination, memory, inference-making and other elements (Nikolajeva 2014a: 227). For Nikolajeva, the concept of 'embodiment' helps to explain why readers can become so invested with marks on a page: it is because engagement with fiction 'is firmly anchored in the body' (Nikolajeva 2014a: 10). Whether or not characters' emotions are explicitly represented, when they are connected to body movement and sensory perceptions which readers recognize, even young children can infer what those emotions might be (Nikolajeva 2014a:134).

Nikolajeva highlights that engagement with fiction also occurs 'in the body's position in space and time' (Nikolajeva 2014a: 10). I will argue that this is important because both fictional texts and real accounts of the refugee experience often refer to a sense of spatial dislocation and temporal distortion. This happens as a result of physical movement through different places and landscapes and across material and political borders, often in discomfort or pain and without a clear sense of geographical location or destination results. While spatiotemporal distortion can also occur during forced confinement, for example in a refugee camp or detention centre, in this article I will only consider it in relation to forced walking. I will use Bakhtin's notion of the literary 'chronotope' which describes the temporal and spatial relationships in a narrative (Bakhtin 1981: 84) and, more importantly in this case, the characters' perception of reality. The use of the chronotope can also help understand that 'literary mimesis is grounded in a valuated and emotionally experienced fictional world' as it 'points at the spatial and temporal embedding of human action' in this world (Bemong, 
Borghart, De Dobbeleer, Demoen, De Temmerman and Keunen 2010: iv). In refugee texts, references to dislocation or distortion can be inscribed in this chronotope of forced migration, where the character's position in space and time is impacted by distance, unfamiliar and difficult terrain and the elements and the act of walking without a clear destination. This chronotope is useful to identify some aspects of the refugee experience and how it becomes part of the fictional experience of the reader.

The theories referred to above all support the idea that when stories are set in contexts and circumstances that are less familiar to non-refugee readers, such as the often harsh and dangerous conditions of the refugee experience, an object like a shoe which is familiar and alludes to previous experiences and recognizable physical sensations, together with an account of a physical act like walking, can activate a connection between mental states, emotions and their physical expressions, thus engendering both cognitive and affective empathy. The refugee texts I have selected to exemplify this are four picturebooks and three pre-teen/early teenage novels (approximately between 10 and 14 years old), published in the UK and the US since 2005 and set in different areas of the world - Europe, Latin America, the Middle East, Australia and Africa. They are generally representative of the type of narrative plots around forced displacement and reflect issues in all three stages of the refugee experience (Fazel and Stein 2002). Two of the books are set in refugee camps and all but one of the five books are about characters 'on the move' are explicitly about refugees as defined by the 1951 Refugee Convention (UNHCR 1967).

\section{Shoes and the impact of forced walking in refugee texts}

In books about the refugee experience, there are often textual and visual references to characters walking long distances in order to reach a place of safety. These include references 
to affective mental states such as fear, grief and despair but also to the physical effects of forced and hurried walking on hostile terrain on the body. Highly emotive words are designed to engage the reader's emotions, such as the frequent use of the verbs 'stumbling', 'tripping', 'staggering', 'falling', 'faltering' and 'limping'. The targeted age-group of the readers determines the detail in which the dangers and difficulties of the journeys are described or pictured, with the images often working to create different levels of emotional engagement. This is evident in a picturebook for younger children, My Shoes and I, written by Colato Laínez and illustrated by Vanden Broeck (2010), which glosses over the impact of the dangers and difficulties of the migrant journey by displacing them on to a pair of new shoes. In this first-person narration of Mario's journey with his father, from his home in El Salvador to the United States to join his mother, shoes become the material social agents (Dant 1999) mediating between the character and his experiences. There is no explanation of why they must leave their country; they may be economic migrants rather than refugees but there is a sense of urgency which suggests they may be fleeing from violence. Father and son travel through Guatemala and then Mexico, going as far as buses will take them and then they must walk, crossing mountains and a river, following the path of many other migrants from Central America.

Throughout the journey, Mario's shoes become different imaginary objects such as cars or submarines that move forward with him, and the relationship he develops with his shoes helps him to endure the physical impact of the journey. As they become dirty, worn and broken, he comforts them using a nursery rhyme in Spanish often recited to children when they hurt themselves: 'Sana, sana, colita de rana', thus distancing himself from his own exhaustion and pain. The reader is also allowed some distance from reality by the use of unusual and intense colours for the landscape, but the swirling coloured lines in the desert 
and the river allude to the potential danger and the impact of these elements on the body and on Mario's shoes. The rhythm and pace of the short sentences also convey movement, especially in the following section where the narrative is pared down to the minimum. There is nothing else but the person and the action and the movement forward becomes halting, repetitive and exhausting: 'We run. We stop. We fall down. We get up. We walk. We rest. We run again.' (Colato Laínez and Vanden Broeck 2010: np). The transaction (Rosenblatt 1978) with the visual and written text to which young children bring their experience of desirable but easily damaged objects like shoes (Riello and McNeil 2006) opens a range of emotions for readers to infer (Nikolajeva 2014a) along with a sense of physical and temporal disruption. At the same time the focus on the material object provides some distance from the reality which may prove too upsetting.

A similar textual and visual experience of movement is conveyed in another picturebook which, although not focused on shoes, suggests the mental and physical exhaustion of forced mobility on a child. The Day the War Came, written by Davies and illustrated by Cobb (2018), is also told in the first person, by an unnamed little girl. After 'the war came' we see her on a double-page spread divided into three horizontal strips that accentuate the sense of movement, fleeing from a city in flames; being helped on to a truck full of people; and finally, wearing an orange life-vest, wading away from an overloaded refugee boat towards a beach. The terrain and landscape features are only sketchily drawn, but the image strips and the perspective emphasize a sense of long distances and vast spaces as well as haste, confusion and fear. Earlier the text has used the words 'ragged' and 'bloody' to describe her and now the mud and rain have dirtied her face and clothes and her hair is escaping from her once neat braids. These corporeal and material details are important because they highlight to the reader 
there is no adult left to help her with daily physical and material tasks such as washing and combing or with emotional coping.

As in My Shoes and I, the use of words and phrases on this spread are also short and halting, with adjectives that indicate physical discomfort, danger and death:

I ran. Walked over fields and roads and mountains

in the cold and mud and rain;

rode on the back of trucks, in buses;

went on a boat that leaked and almost sank;

then a beach where shoes lay empty on the sand. (Davies and Cobb 2018: np)

In the accompanying illustration, the 'empty' shoes are red and stand out in the rain-swept waves; they look as if they had belonged to an even younger child than herself, perhaps acting, for the adult reader, as testimony to the death of real children like Alan Kurdi. Although it is left to the reader to imagine what happened to their owner, the visual details (Nikolajeva 2014b) of the little girl's facial expression and in her gesture of holding a hand over her mouth as she reaches over a shoe, compel the reader to share the powerful emotions she is going through.

Also focusing on the emotions of one character amidst images of groups is another picturebook, Marwan's Journey written by de Arias and illustrated by Borràs (2018). The boy's narrative of fleeing from war somewhere in the Middle East is depicted through the images and poetic language, with the verb 'to walk' and the word 'footsteps' appearing repeatedly. It is suggested that Marwan's mother has died in the war, but he continues to hear 
her voice urging him to 'keep going, walk and walk and walk' and not look back. He keeps walking along with 'hundreds of people, thousands of feet, one before the other' (de Arias 2018) and the visual images of blank or sad faces on one spread and bare feet on desert sands on another spread underscore the textual references to forced walking with the strangers who share the experience of grief and loss. This picturebook is another example of how the wordimage interaction (Nodelman 1988) can be a powerful way to cognitively and affectively engage readers with fiction (Nikolajeva 2014a).

Working together with the images as well as the first-person narratives, the sensory descriptions involving shoes and walking allow authors to effectively highlight the effects of pain on the feet, bringing this physical experience close to the readers. Mario's language may be 'child-like' because of the simple words and the short sentences, but they convey his physical and mental distress, both for himself and his ruined shoes:

I feel something hurting my feet. Something is inside my shoes. I lift my feet. Holes! Round, bad, horrible holes are in the soles of my shoes. There are pebbles between my toes. There are tears in my eyes. (np)

When shoes as extended parts of the body cease to protect from the environment (Riello and McNeil 2006), losing them implies a physical and emotional loss which any reader may relate to, but which become more serious in the case of real-life journeys.

Similar pain, exhaustion and temporal dislocation are described more directly and in more detail in books for older readers, for example, in A Long Walk to Water by Park (2010) which is about an 11-year-old boy who is separated from his family as he flees the armed conflict in Southern Sudan. Based on the real-life story of Salva Dut, the narrative describes his journey across different terrains, a forced march which includes a climactic scene in which he crosses 
the Akobo desert. The uselessness of the materials that his shoes are made of, already a sign of material poverty (Riello and McNeil 2006), becomes evident as he enters this terrain, and his shoes cease to protect him and cause pain:

Salva's shoes stood no chance against the hot stony desert ground. The soles, made from rubber tire treads, had already been reduced to shreds held together with a little leather and great deal of hope. After only a few minutes, Salva had to kick off the flapping shreds and continue barefoot [...] Thorns gored his feet. His lips became cracked and parched. (Park 2010: 52-3)

Eventually, the contact of bare feet and stone brings Salva to breaking point and he starts to cry:

[...] Salva stubbed his bare toe on a rock, and his whole toenail came off. The pain was terrible. Salva tried to bite his lip, but the awfulness of that never-ending day was too much for him. He lowered his head, and the tears began to flow. (Park 2010: 53)

These passages exemplify how the narrative can vividly bring the impact of the desert conditions on the body to the reader through adjectives like 'hot', 'stony', 'cracked' and 'parched', as well as in the description of the pain of a stubbed toe, all physical sensations which in the act of reading most readers are likely to relate to in some way (Rosenblatt 1978). The effects of being forced to walk long distances is depicted in one of the four interlocking stories in Refugee (Gratz 2017) which centres on 14-year-old Mahmoud and his family fleeing from the Syrian War. After almost drowning in the Mediterranean, they are rescued by the Coast Guard and set down in Lesbos. Mahmoud's father, ever pragmatic, asks Mahmoud to check the bodies on the beach to see if they have any shoes that fit (just as 
Enaiatollah did in Geda's (2012) nonfictional account). Making their way to Hungary, the family is detained in a refugee camp and about to be deported to Serbia. Mahmoud seizes his chance when UN inspectors arrive at the camp: he simply stands up and walks through the door opened for the inspectors. The act of walking is courageous and represents the agency to resist rather than submit to displacement, but the physical and mental stress that results from walking for hours without stopping:

[...] this walk quickly seemed endless. They had no water and no food, and Mahmoud's stomach growled and his lips were dry. He felt like one of the zombies from his favourite video game. All he wanted to do was lie down and sleep, but Mahmoud knew they couldn't stop. If they stopped, the Hungarians would arrest them. They had to keep moving forward. Always forward. Even if it killed him. (Gratz 2017: 301)

As in the description cited above from A Long Walk to Water (Park 2010) the 'embodied simulation' (Bergen 2016) here relies on the readers' recognition of that sensation of tiredness when time stretches out. The reference to zombies is another association for a young reader to make, as it conjures up an image of the slow and staggering trudge of the group of migrants, but it also serves as a reminder that Mahmoud is just a young boy who, like many young people, enjoys playing video games. The reference brings home the possibility of any 'normal' teenager's life being disrupted by war closer to home.

The reference to zombies and the 'endless' walk is echoed in some of the other refugee texts mentioned here where the chronotope of forced migration emphasizes the spatio-temporal dislocation caused by the disruption to everyday 'normal' life. Time and space become distorted or even meaningless as characters flee and are forced to keep moving. This clearly 
comes across in Long Walk to Water because in the desert, time is altered: 'it felt like the longest day Salva had ever lived through'; the sun was 'eternal' and 'each minute of walking in that arid heat felt like an hour' (Park 2010: 52). Similarly, in Marwan's Journey (de Arias 2018) Marwan does not know where he is or where he is going, and the effect of this forced walking on his perception of time comes across through the repeated use of a simple and short phrase which triggers a sensation of the endless repetitive movement and which, similarly to My Shoes and I, is stretched out, in this case by the ellipsis on two consecutive spreads: 'then we walked, one day, two... three...' [...] 'One... two... three...' (de Arias 2018: np).

\section{Footwear as metaphor in contexts of detention}

Other children's and young adult books refer to the experience of migration by depicting another of its aspects: life in a refugee camp. They are about characters who have had to stop walking for a variety of reasons, including being forcefully prevented by immigration police and other authorities. In these narratives, lacking or having shoes takes on metaphorical implications, especially in terms of mobility. At the core of the picturebook, Four Feet Two Sandals, written by Williams and Mohammed, and illustrated by Chayka (2007), is the idea that shoes in a camp acquire a different kind of value as material possessions that signal some form of agency and the possibility that the character might be able to move forward again. This picturebook invites the reader to imagine day to day life for a child in a refugee camp in Peshawar, with the repeated actions of washing clothes or standing in the 'long line' for water, reflecting the consequences of loss of mobility. The words tell this story as a straightforward narrative and the pastel images convey the desert landscape of the refugee camp, with some brighter colours contrasting with the monochrome desert background. The pastels soften the harshness of life in the camp, but they suggest and support the difficulties that the words spell 
out more clearly, by referring to the impact of the walking to get to the camp on the feet and footwear:

The girl only stared [...] Her feet were cracked and swollen, as Lina's had been when she first arrived in camp [...] In the morning Lina went to do the washing, wearing one beautiful sandal. She picked her way to the stream, careful to keep her sandal out of the filth. Her old shoes had been ruined on the many miles of walking from Afghanistan to Peshawar, the refugee camp in Pakistan. (Williams, Mohammed and Chayka 2007: np)

Lina only has one sandal because, after a scrabble for donated clothing, she and another girl find themselves holding one sandal each of the same pair and the story is about how this leads to a strong friendship between them.

In a novel for older readers about life in a detention centre for immigrants, The Bone Sparrow by Fraillon (2016), shoes also become markers, 'indexing the status and/or agency of the migrant' (Basu and Coleman 323). Subhi is a Rohingya boy who was born and has lived all his ten years of life in a detention centre in Australia. He knows little of the world outside the camp and the tedium of his day-to-day activities is only alleviated through his imagination and his stories. Through Subhi's words, which often refer to sight, touch and taste, the reader glimpses what life is like in a hostile geographical and political landscape. He speaks of stones and the heat 'poking' and 'eating' his bare feet and he lives in constant fear of being separated from his mother and sister and being put into the section reserved for older males. When one of the guards catches him doing something against the rules, at first all he can see is 'black boots flashing from the sun' (Fraillon 2016: 37), a symbol of the power and cruelty of authority. The 'embodied simulation' (Bergen 2016) here is further developed through 
references to the senses: the guard's hand reaching for him is described as 'hard and scratchy, grabbing at my shirt and pulling me towards him so that my teeth clang on my tongue and I can taste blood' (Fraillon 2016: 43). Subhi's sister, Queeny, distracts the guard who lets him go but not before spitting on to the dirt and on Queeny's foot. Subhi's narrative continues, 'Then he walks away. I can feel tears snaking down my cheeks and Queeny's arm wraps around me...' (Fraillon 2016: 44). The violence, tears and hugs create that 'deeply-felt simulation of social experience' (Mar, Oatley and Petersen 2009) and an awareness that Subhi is just like any ten-year-old boy who has been bullied.

The moment that Subhi eventually manages to get some shoes becomes a turning point in the novel:

There are only fourteen pairs of real shoes in this whole entire camp, even though there must be near about nine hundred pairs of feet. And one of those pairs of shoes belongs to me. My shoes are blue with white laces and some black bits on the side. They were more than big enough when I first got them and I still have to stuff paper in them to stop them from falling off with each step. I'm growing into them, though. (Fraillon 2016: 33)

It may be hard for a reader to imagine what life in detention is like but the simple statistic about the number of shoes and the excitement of having new shoes which readers will be able to relate to, brings home the reality of these spaces and the difficulties of moving forward. At least there is a suggestion of hope in that there is room for Subhi to 'grow into' his shoes and perhaps leave the detention centre and move on. 


\section{Moving forward with the characters}

Not all emotions and physical sensations are negative in these seven refugee texts; there are plenty of moments of humour, solidarity, love and hope which the reader can relate to from their own (hopefully) more positive experiences (Rosenblatt 1978). In My Shoes and I, for example, the last image shows Mario's family together and unharmed, an almost miraculous reunion which is enhanced by the traditional ex-voto style of painting in this picturebook, one that reflects the migrant's need for protection and their prayers for a safe journey (2). The family hug reinforces Mario's happiness (despite his broken shoes) and triggers empathy through the reader's feelings in similar but less desperate situations.

The sandals in Four Feet Two Sandals end up by creating a strong bond between Lina and Feroza, both of whom also share experiences of losing family members; however, the story does not dwell on the loss - but on the girls' growing friendship and their dreams of leaving the camp. At first, the girls are reluctant to part with their one sandal, but eventually they decide to share them, exchanging them every other day, literally walking in each other's shoes. The image of the sandals, their newness and then their wear and tear, signals the length of time that refugees must wait to be resettled. When Lina's mother's name finally appeared on the list of those going 'to America', Feroza takes the sandals off, 'You cannot go barefoot to America', she tells her friend. However, with the granting of refugee status come new shoes, not sandals but 'black leather' shoes, a detail that emphasizes the fact that without proper shoes, there is no leaving the camp. In an unlikely twist, given that in reality a girl like Feroza's circumstances would probably keep the much-needed sandals, the girls decide to each keep one as testimony to their friendship. 
In the texts for older readers there are also positive moments, such as the moment in Long Walk to Water where when Salva shares his worries that he'll never find his family if he goes to Ethiopia with his friend Martial. Martial puts his arm around Salva's shoulders and says,

“It doesn't matter. Don’t you know that if we keep walking east, we'll go all the way around the world and come right back here to Sudan? That's when we'll find our families!" Salva had to laugh. They were both laughing as they started walking again, arm in arm, their strides matching perfectly. (Park 2010: 30-31)

This short passage not only serves both Salva and the reader as a respite from the character's fears and loneliness but also to illustrate how understanding these feelings in someone else can allow the use of gentle humour to support that person. All readers can relate to friendship bonds and in this case Martial's empathetic response is embodied in laughter, gestures and movement. The metaphor of walking together and, what's more, with 'matching' strides, creates a mental image that confirms their relationship and the strength of their developing friendship.

In the case of Refugee, the author has chosen to highlight the character's resilience and agency because Mahmoud's decisive step forward is taken alone, motivated by the realization that his parents are too 'broken' to take the lead and that if he does not 'stand up', the family would again be forced to move, but backwards, towards conflict instead of refuge. In the emotional scenes that follow, the reader virtually accompanies Mahmoud step by step. Although the Hungarian detention centre guard cries out at him to stop and even starts to raise her gun, Mahmoud knows she won't shoot in front of the inspectors: 'Mahmoud stepped outside $[\ldots]$ Mahmoud took another step, and another, and soon he was away from the building, walking toward the road' (Gratz 2017: 283). As the rest of the adults and children 
from the detention centre follow him, the police threaten to arrest them, but nobody stops walking.

In these and other texts, shoes and walking take on a new meaning when characters reach their destination or begin to look to the future. At the simplest level, new shoes represent a 'new' life and suggest new economic and social possibilities. They are linked to freedom of movement and to having the option of walking in the direction of one's choice. In the case of Salva Dut in A Long Walk to Water, his choice was to eventually head back to Sudan, but this time as a leader of a non-profit organization working to provide fresh water to villages.

\section{Conclusion: The potential of refugee texts for fostering empathy}

The growing number of refugee texts provide a rich and important resource for raising awareness about diverse contexts of migration, yet the claims generally made about the potential of these texts for increasing understanding and empathy are often made without substantial evidence. On the one hand, critical work on refugee texts has tended to focus more on the literary aspects of the texts rather than on how these might work in terms of bringing the reality of the refugee experience closer to the reader and encouraging cognitive and affective empathy. On the other hand, empirical studies (Arizpe, Bagelman, Devlin, Farrell and McAdam 2014, Hope 2017, McAdam 2018) have provided some evidence which suggests that, with a mediating adult, it is possible to not only to develop affective empathy but also empathic concern to encourage social action. Yet there is still a lot of work to do in order to not only to demonstrate the links between children's literature and empathy but also examine closely what empathy in this context might mean and lead to. One of the first steps is to analyse the aesthetic and literary mechanisms of refugee texts to see how they create connections with their readers. 
In this article, I have provided a literary analysis that looks at how these connections are made through references to material objects and physical movement that mediate meaning (Dant 1999) within the texts and refer back to the reality of the migrant journey conveyed in real-life accounts. Within the corpus of refugee texts, I located three main themes - the shoe as material testimony, the effects of forced walking on the body and spatio-temporal dislocation - which are closely interrelated with aspects of materiality and mobility (or immobility), as well as temporality (Basu and Coleman 2001: 321). By looking at the connections that these themes generate through, first, the lens of material studies and second, the lens of cognitive narratology, it is possible to see how textual and visual references both position shoes as material testimony to the refugee experience and at the same time encourage life-to-text and text-to-life associations, creating an 'embodied simulation' (Bergen 2016) of this experience and encouraging cognitive and affective empathy (Nikolajeva 2014a).

As the extracts from the refugee texts above suggest, the descriptions of the physical impact of the hostile terrain or extreme environmental conditions on shoes turn them into material witness of the dangers and difficulties of the journeys. The reader is invited to imagine these journeys through textual and visual expressions that appeal to the sense of touch on the soles of the foot when walking either in uncomfortable shoes or in bare feet, and convey the physical sensation of the temperature and texture of natural elements such as such as snow, mud, water, stones, thorns or sand. The descriptions of weariness and exhaustion and the temporal and spatial dislocation that are at the centre of the chronotope of forced displacement increase emotional investment in the text. The reader is invited to empathize with Mario's and Salva's tears, with Subhi's fears or with Mahmoud's desperation 
(Nikolajeva 2014a \& b) as they find themselves in hostile places for children, far from the safety and comfort of home.

Further metaphors to do with shoes, which this article did not have room to address, raise questions about what childhood means in contexts of migration, such as the unasked-for initiation into adulthood as minors are forced to take on experiences, responsibilities and emotions which they are too young for, either because their parents are missing or cannot cope -another common experience for refugees (Fazel and Stein 2002). This can be seen in The Day the War Came but also in the first words in Marwan's Journey which accent this forced transition: 'I take giant steps/ even though I am small' (de Arias and Borràs, 2018, np). The refugees must 'step into the shoes' of adults and confront challenges of the adult world, perhaps prompting readers to imagine how they would react in similar circumstances.

Like other objects of material culture, shoes 'tie us to others in our society' (Dant 1999: 2) and can 'speak' or become testimony for those others. When fiction invites readers to 'walk in other's shoes', the emotional investment might then lead to questions from the reader about the character's plight, about why they are forced to leave their homes and must undergo these journeys or why they are not allowed to move freely. Writing about what he calls the 'other-shoe imaginative experience', Walton argues that 'our responses to works of fiction are, not uncommonly, more highly charged emotionally than our reactions to actual situations and people of the kinds the work portrays' (Walton 2015: 275). This would suggest that, for their intended audience, these children's and young adult's books are probably more effective in eliciting a sensitive response than, for example, stories in the news.

This article has attempted to examine the work of narrative strategies which are intended to encourage empathy. Like Mar and Oatley (Mar, Oatley and Petersen 2009), I believe that 
literature can lead to better social understanding and, like Batson (2009), I would argue that what matters is that we can begin to understand the processes 'whereby one person can come to know the internal state of another and can be motivated to respond with sensitive care' (Batson 2009: 11). If we examine how these processes work for readers and how the aesthetic and literary strategies that seek to expand the readers' cognitive and affective experiences work, then we can better support the claims made for children's literature in the development of empathy as well as the pedagogical use of this literature by teachers and other professionals in the classroom and other educational spaces.

Conflict of interest statement: None declared.

\section{Notes}

1. In this article I am considering readers who have not undergone the experience of being a refugee; the experience of readers of refugee texts who are or have been refugees themselves deserves a study of its own.

2. A legacy of Spanish Catholicism in Mexico, votive paintings in their popular form usually represent either a promise in return for saintly intervention or gratitude for an or answered prayer and the image usually represents the moment of this 'miracle'. Made on small rectangular pieces of metal or wood, they are painted in vivid, primary colours. Ex-votos in different forms (e.g. photographs) are still associated with migration. (Luque and Beltran 2001).

\section{References}


1. Arizpe, E. and Styles, M. (2003) Children Reading Pictures: Interpreting Visual Texts, London: Routledge.

2. Arizpe, E., Bagelman, C., Devlin, A. M., Farrell, M. and McAdam, J. E. (2014)

'Visualising Intercultural Literacy: Engaging critically with diversity and migration in the classroom through an image-based approach', Language and Intercultural Communication, 14/3:304-321.

3. Bakhtin, M. M. (1981) The Dialogic Imagination: Four essays. Ed. Michael Holquist. Trans. Caryl Emerson and Michael Holquist.1981. Austin: University of Texas Press.

4. Basu, P. and Coleman, S. (2008) Introduction: Migrant Worlds, Material Cultures. Mobilities, 3/3: 313-330.

5. Batson, D. (2009) 'These Things Called Empathy: Eight Related but Distinct Phenomena', in Batson, D., Decety J. and Ickes, W. (eds) The Social Neuroscience of Empathy, published to MIT Press Scholarship Online: August 2013.

6. Bemong, N., Borghart, P., De Dobbeleer, M., Demoen, K., De Temmerman, K. and Keunen, B. (2010) 'Preface'. Bakhtin's Theory of the Literary Chronotope: Reflections, applications, perspectives. Gent: Academia Press.

7. Bergen, B. (2016) 'Embodiment, Simulation and Meaning', in Riemer, N. (ed) The Routledge Handbook of Semantics, Abingdon: Routledge.

8. Colato Lainez, R. and Vanden Broeck, F. (2010) My Shoes and I. Honesdale, PA: Boyds Mill Press.

9. Dant, T. (1999) Material Culture in the Social World. Buckingham: Open University Press.

10. Davies, N. and Cobb, R. (2018) The Day War Came. London: Walker Books.

11. De Arias, P. and Borràs, L. (2018) Marwan's Journey. Hong Kong: Minedition. 
12. De León, J. (2015) The Land of Open Graves. California: University of California Press.

13. Dolan, A. M. (2014) You, Me and Diversity: Picturebooks for teaching development and intercultural education. London: Trentham Books.

14. Evans, J. (2015) ‘Could This Happen To Us?: Children's Critical Responses to Issues of Migration in Picturebooks', in Evans, J. (ed) Challenging and Controversial Picturebooks, 243-259. London: Routledge.

15. Fazel, M. and Stein, A. (2002) 'The Mental Health of Refugee Children', Archives of Disease in Childhood, 87: 366-370.

16. Fraillon, Z. (2017) The Bone Sparrow. London: Orion Children's Books.

17. Gee, J. P. (2001) 'Reading as Situated Language: A Sociocognitive Perspective', Journal of Adolescent and Adult Literacy, 44/8: 714-725.

18. Geda, F. (Translated by Curtis, H.) (2012) In the Sea there are Crocodiles. London: David Fickling Books.

19. Giuffrida, A. (2018) 'French police cut soles off migrant children's shoes, claims Oxfam', The Guardian 14 June 2018, accessed 26 August 2018.

20. Gratz, A. (2017) Refugee. New York: Scholastic Press.

21. Hope, J. (2017) Children's Literature About Refugees. London: UCL/IOE Press.

22. Independent (2018) 'Algeria accused of abandoning more than 13,000 migrants in Sahara Desert without food or water', 25 June 2018, accessed 26 August 2018.

23. Iser, W. (1978) The Act of Reading: A Theory of Aesthetic Response. London: Johns Hopkins University Press.

24. Lee, H. (1977) To Kill a Mockingbird. Arrow Books: London. 
25. Luque, E. and Beltran, M. M. (2001) 'Powerful Images Mexican Ex-votos', in Netto Calil Zarur, E. and Lovell C. M. (eds) Art and Faith in Mexico, pp. 69-77. Albuquerque: University of New Mexico Press.

26. Mallan, K. (2013) 'Empathy: Narrative empathy and children's literature', in Wu, Y., Mallan, K. and McGillis, R. (eds) (Re)imagining the world, 105-114. New York: Springer.

27. Mar, R. A., Oatley, K. and Petersen, J. B. (2009) Exploring the link between reading fiction and empathy: Ruling out individual differences and examining outcomes Communications 34: 407-428.

28. McAdam, J. E. (2018) 'Narratives of change: the role of storytelling, artefacts and children's literature in building communities of inquiry that care', Cambridge Journal of Education, online, accessed 8 March 2019.

29. Menjívar, C. and Perreira, K. M. (2017) 'Undocumented and unaccompanied: children of migration in the European Union and the United State's, Journal of Ethnic and Migration Studies (published online 21 Dec) accessed 27August 2018.

30. Nel, P. (2018) 'Introduction: Migration, Refugees, and Diaspora in Children's Literature', Children's Literature Association Quarterly, 43/4: 357-362.

31. Nikolajeva, M. (2014a) Reading for learning: Cognitive approaches to children's literature. Amsterdam: John Benjamins Publishing Company.

32. Nikolajeva, M. (2014b) '"The Penguin Looked Sad". Picturebooks, Empathy and Theory of Mind', in Kümmerling-Meibauer (ed) Picturebooks: Representation and narration. London: Routledge.

33. Nikolajeva, M. and Scott, C. (2006). How Picturebooks Work. Abingdon: Routledge. 
34. Nodelman, P. (1988) Words about Pictures: The Narrative Art of Picture Books. Athens, GA: University of Georgia Press.

35. Oatley, K. (2016) 'Fiction: Simulation of Social Worlds', Trends in Cognitive Sciences, 20/8: 618-628.

36. Park, L. S. (2010) A Long Walk to Water. New York: Clarion Books.

37. Pogrebin, R. (2016) 'Ai Weiwei Melds Art and Activism in Shows About Displacement', The New York Times, 20 October, accessed 27 August 2018.

38. Quackenbush, C. (2018) '7,000 Pairs of Shoes Laid on the Capitol Lawn to Represent Children Killed by Gun Violence'. Time, March 14, accessed 27 August 2018.

39. Riello, G. and McNeil, P. (eds) (2006) Shoes: A history from sandals to sneakers. Oxford and New York: Berg.

40. Rosenblatt, L. M. (1978) The Reader, The Text, The Poem. Carbondale, IL: Southern Illinois University Press.

41. Seelinger-Trites, R. (2017) 'Cognitive Narratology and Adolescent Fiction', in Beauvais, C. and Nikolajeva, M. (eds) The Edinburgh Companion to Children's Literature, Edinburgh: Edinburgh University Press.

42. Sepetys, R. (2016) Salt to the Sea. London: Penguin Books.

43. Thomson, G. (2003) 'Crossing with Strangers: Children at the Border; Littlest Immigrants, Left in Hands of Smugglers', The New York Times, 3 November, accessed 26 August 2018.

44. UNICEF (2018) Child Displacement. https://data.unicef.org/topic/child-migrationand-displacement/displacement/, accessed 31 August 2019.

45. UNHCR Website. United Nations Convention and Protocol Relating to the Status of Refugees. http://www.unhcr.org/3b66c2aa10.html, accessed 8 March 2019. 
46. Walton, K. L. (2015) In Other Shoes. New York: Oxford University Press.

47. Williams, K. L., Mohammed, K., and Chayka, D. (2007) Four Feet, Two Sandals. Michigan: Eerdman's Books for Young Readers. 